\title{
Latent Class Analysis of Antisocial Behavior: Interaction of Serotonin Transporter Genotype and Maltreatment
}

\author{
James J. Li • Steve S. Lee
}

Published online: 20 April 2010

(C) The Author(s) 2010. This article is published with open access at Springerlink.com

\begin{abstract}
To improve understanding about genetic and environmental influences on antisocial behavior (ASB), we tested the association of the 44-base pair polymorphism of the serotonin transporter gene (5-HTTLPR) and maltreatment using latent class analysis in 2,488 boys and girls from Wave 1 of the National Longitudinal Study of Adolescent Health. In boys, ASB was defined by three classes (Exclusive Covert, Mixed Covert and Overt, and No Problems) whereas in girls, ASB was defined by two classes (Exclusive Covert, No Problems). In boys, 5HTTLPR and maltreatment were not significantly related to ASB. However, in girls, maltreatment, but not 5HTTLPR, was significantly associated with ASB. A significant interaction between 5-HTTLPR and maltreatment was also observed, where maltreated girls homozygous for the short allele were 12 times more likely to be classified in the Exclusive Covert group than in the No Problems group. Structural differences in the latent structure of ASB at Wave 2 and Wave 3 prevented repeat LCA modeling. However, using counts of ASB, 5-HTTLPR, maltreatment, and its interaction were unrelated to overt and covert ASB at Wave 2 and only maltreatment was related to covert ASB at Wave 3. We discuss these findings within the context of sex differences in ASB and relevant models of gene-environment interplay across developmental periods.
\end{abstract}

This work was supported by the Consortium for Neuropsychiatric Phenomics (NIH Roadmap for Medical Research grants UL1-DE019580, RL1DA024853).

J. J. Li $\cdot$ S. S. Lee $(\bowtie)$

Department of Psychology, University of California,

Los Angeles (UCLA),

1285 Franz Hall, Box 951563, Los Angeles,

CA 90095-1563, USA

e-mail: stevelee@psych.ucla.edu
Keywords Antisocial behavior - Serotonin - Sex

differences $\cdot$ Maltreatment $\cdot$ Gene-environment interaction

Antisocial behavior (ASB) is defined by acts that violate established norms/rules (e.g., truancy, curfew), aggression resulting in interpersonal harm (e.g., violence, assault), or property damage (e.g., fire setting) (Dishion and Patterson 2006). ASB is one of the most common referrals for youth mental health services in the United States (Kazdin et al. 2006). Disruptive behavior disorders, including oppositional defiant disorder (ODD) and attention-deficit/hyperactivity disorder (ADHD), were the most prevalent disorders in an epidemiological sample of 4 year-old children (Lavigne et al. 2009). Externalizing behavior is clinically significant because it strongly predicts academic failure and adult psychopathology (e.g., antisocial personality disorder) and it is highly persistent over time (Farrington 1995). In fact, stability estimates for aggression and ASB are comparable to IQ, which has long been considered as one of the most stable individual attributes (Olweus 1979). ASB is also responsible for significant economic consequences. In the United States, the cost of health care, academic support, and juvenile justice was approximately $\$ 70,000$ more for youths with conduct disorder (CD) than youth without CD over a seven year period (Foster and Jones 2005). Thus, ASB is an important constellation of problems with clinical and public health significance.

Existing models have differentiated dimensions of ASB based on separable risk factors, underlying mechanisms, and divergent patterns of association, including overt (e.g., fighting, bullying) and covert (e.g., lying, stealing) ASB (Loeber and Schmaling 1985; Frick et al. 1993). In a study of 391 preschool children, overt ASB was more strongly associated with hyperactivity, conduct problems, and 
classroom conflict than covert ASB (Willoughby et al. 2001). In two separate samples of boys and girls with and without ADHD, a laboratory measure of childhood covert ASB prospectively predicted adolescent delinquency severity 4-5 years later, controlling for initial ADHD, overt aggression, and noncompliance (Lee and Hinshaw 2004, 2006). A recent meta-analysis also suggests that genetic influences are substantially stronger for overt ASB than for covert ASB (Burt 2009).

ASB also shows divergent patterns of association based on its age of onset. Moffitt (1993) proposed two distinct types of antisocial youth: life-course-persistent (LCP) and adolescent-limited (AL). The LCP pathway is significantly heritable, frequently comorbid with ADHD, and correlated with physical aggression, neuropsychological deficits, and parent psychopathology (Aguilar et al. 2000; Moffitt and Caspi 2001). There is also evidence that LCP children have higher levels of callous and unemotional traits (e.g., low guilt, lack of empathy, less sensitive to punishment), which is also predictive of aggression and delinquency (Frick et al. 2003). In contrast, the AL pathway is associated with a post-pubertal onset of ASB, desistance by late adolescence, relatively few child and family risk factors, and a predominance of non-aggressive offending (e.g., status offenses). This pathway is driven predominantly by social processes (e.g., deviant peer influences) and personality factors (e.g., sensation seeking) (Moffitt 1993). Evidence of a third subtype of ASB has also emerged (Moffitt et al. 2008). Compared to LCP and AL youth, Odgers et al. (2008) found that the childhood-limited group had more child conduct problems, but that these behaviors declined by mid-adolescence. The prognosis for this group is poorly understood, however (Odgers et al. 2007).

\section{Sex Differences in ASB}

Although some theories of ASB converge with patterns of ASB observed in girls (Keenan et al. 1999), most studies have focused on boys (Lahey et al. 1999), despite important sex differences (Loeber and Stouthamer-Loeber 1998; Silverthorn and Frick 1999). For example, girls are less physically aggressive than boys (Silverthorn and Frick 1999) and CD is two- to four-times more common in boys than in girls (Cohen et al. 1993). However, sex differences in ASB narrow significantly by early adolescence with girls, whose ASB begins in adolescence, showing worse outcomes than boys with a similar onset (Fergusson et al. 2005). This convergence is largely explained by girls engaging in non-aggressive ASB, including relational ASB (i.e., spreading rumors, gossip, ostracizing peers) that are comparable to boys. For example, in the Dunedin birth cohort, rates of non-aggressive ASB were equivalent in boys and girls at age 15, but boys were 3-4 times more physically aggressive than girls (Moffitt et al. 2001). In another study of 13,000 5-11 year-old children, girls and boys were equal in physical aggression at age 5 , but by age 11 , female aggression decreased whereas aggression in boys remained stable (Lee et al. 2007). Hipwell et al. (2002) found that older girls showed higher rates of oppositional/defiant behaviors and relational aggression than younger girls in a community sample of 2,451 girls (aged 5 to 8), suggesting that non-aggressive ASB increases with age in girls. Overall, the literature suggests that age of onset and the type of ASB are central to understanding ASB across development.

\section{Latent Class Analysis}

Empirically-derived approaches that identify subgroups of antisocial youth are heuristic for several reasons, including the value of person-centered strategies (Bergman and Magnusson 1997). Taxonomies traditionally assume homogeneity within a group, although thresholds may be arbitrary or inaccurate (Schwartz et al. 2001). For example, children who fall just short of diagnostic criteria for $\mathrm{CD}$ and ODD are equally impaired as children who meet full criteria (Levin 2008). Similarly, frequent comorbidity challenges the assumption of homogeneity within a single disorder, as evidenced by the fact that adolescents with $\mathrm{CD}$ frequently have comorbid ADHD, anxiety, and substance disorders (Loeber and Keenan 1994). Compared to singledisorder and non-disordered cases, individuals with comorbidity have worse health outcomes, are more treatment resistant, and more functionally impaired (Newman et al. 1998). Thus, single-disorder contrasts (e.g., CD vs. controls) may exaggerate effect sizes because of high comorbidity and they may arbitrarily define groups based on theory and clinical observation. However, empiricallydriven approaches have identified groups based on ASB severity and clinical presentation that are not reflected in current diagnostic approaches (Lee et al. 2007; De Nijs et al. 2007; Reinke et al. 2008).

To complement traditional group-based approaches, latent class analysis (LCA) creates a taxonomy based on similar patterns of responses (McCutcheon 1987). Individuals within the same latent class are homogenous and distinct from other classes, provided the indicator variables are locally independent (Magidson and Vermunt 2004). LCA is a relatively anonymous approach where the number of classes is determined through an iterative process where the best fitting model determines the number of independent classes (Magidson and Vermunt 2004). LCA is a more "person-centered" approach, where groups of individuals are prioritized rather than traditional approaches that 
prioritize variable-centered models (e.g., regression). In addition, LCA allows modeling predictors of class membership and the use of covariates (Walrath et al. 2004). Despite these benefits, there are few published LCA studies of ASB. De Nijs et al. (2007) conducted LCA of the Attention Problems, Aggression, and Rule-Breaking Behaviors scales of the Child Behavior Checklist on 1,965 11- to 18-year-old boys and girls referred to university clinics and mental health agencies. Six distinct classes emerged with support for ADHD subtypes, but not for separate aggressive or rule-breaking subtypes. The failure to identify distinct aggressive and rule-breaking dimensions may have been due to referral bias (e.g., clinicreferred youth have an earlier age of onset of problems, more severe psychopathology and impairment) that ultimately obscured these two classes (Goodman et al. 1997). Reinke et al. (2008) utilized LCA with 678 low-income African-American children and found that boys were best characterized by 4 unique classes (Academic Problems, Behavior Problems, Academic and Behavior Problems, and No Problems). Girls were similarly characterized, only without the Behavior Problems group. Girls and boys in the combined group of academic and behavior problems had significantly higher rates of social impairment, suggesting that the groups derived demonstrated expected patterns of association with other domains. However, none of these studies tested specific predictors of group membership.

\section{Serotonin Transporter Gene (5-HTTLPR)}

Genes that regulate serotonin (5-HT) are implicated in aggression across diverse experimental methods and model systems. Although 5-HT functioning has been extensively studied, the precise relationship between 5HT levels and aggression remains unclear (Carrillo et al. 2009). Some studies of 5-HT transporter knockout mice suggest that lower levels of 5-HT in limbic and hypothalamic regions increase aggression (Gibbons et al. 1997; Holmes et al. 2002). Low cerebrospinal spinal fluid of 5-hydroxyindoleacetic acid (5-HIAA), which metabolizes 5-HT, has also been associated with aggression in nonhuman primates (Higley et al. 1996), children with ODD and CD (Van Goozen et al. 1999), and adults with a history of violence (Brown et al. 1979). Conversely, other studies have found that increased 5-HT transmission increases aggression and violent suicidal ideation among depressed, anxious, bipolar, and psychotic patients (Carrillo et al. 2009). Whereas most studies reported an inhibitory effect of 5-HT on aggression (Carrillo et al. 2009), this effect is influenced by the type of aggression assayed as well as other neural and psychosocial factors.
For example, in animal models, 5-HT neurotransmission increased aggression if it was induced by social isolation or stress (i.e., reactive-retaliatory aggression), but it inhibited aggression if the animal was predatory (i.e., proactive-instrumental aggression) (Carrillo et al. 2009). Other neural mechanisms may also be crucial in the context of 5-HT and aggression; for instance, immediately following an attack, mice responded with an increase in prefrontal dopaminergic neurotransmission and a corresponding decrease in 5-HT functioning (Van Erp and Miczek 2000).

The serotonin transporter gene (5-HTTLPR) is of particular interest to ASB because it transcribes proteins which regulate the availability of 5-HT in the brain. In humans, 5-HTTLPR is located on chromosome 17q12 and consists of a 44 base pair (bp) polymorphism, resulting in short (S) and long (L) alleles (Lesch et al. 1996). 5HTTLPR is particularly important to the amygdala, a structure critical to emotion regulation and fear processes (LeDoux 2000), with a recent meta-analysis estimating that 5-HTTLPR accounted for as much as $10 \%$ of the variance in amygdala activation (Munafò et al. 2008). Neuroimaging studies have consistently reported that the $\mathrm{S}$ allele is associated with hyper-reactivity of the amygdala, which is associated with decreased 5-HT transporter functionality (Hariri et al. 2002). Individuals with CD, aggressive traits, and histories of violence are more likely to carry the $\mathrm{S}$ allele (Liao et al. 2004; Haberstick et al. 2006), but null findings have also been reported (Patkar et al. 2002; Sakai et al. 2006). These discrepancies may be due to phenotypic differences in these studies that included sample specific criterion (Sakai et al. 2006), parent and teacher rating scales (Haberstick et al. 2006), and DSM-IV criteria (Liao et al. 2004). Moreover, few studies of 5-HTTLPR have differentiated aggressive and non-aggressive subtypes of ASB. A recent study of 872 male twins found that specific forms of overt and deceptive (e.g., steals, lies, cheats) ASB shared similar risk genes, and that unmeasured environmental factors differentiated their expression (Barker et al. 2009). For example, in addition to genetic factors, negative affect and hostile perception of others were related to aggressive, but not rule breaking, ASB (Burt et al. 2009). A recent meta-analysis of 34 studies found that overt and covert aggression show significant heritability differences (as evidenced by non-overlapping ranges on the $95 \%$ confidence interval) (Burt 2009). This finding is particularly relevant given that most individual studies of heritability of overt and covert ASB were likely under-powered. In light of the different conclusions suggested by the Burt (2009) meta-analysis and the recent large study of twins by Barker et al. (2009), it appears that the precise nature of genetic and environmental influences on different forms of ASB is unknown. 


\section{Gene-Environment Interaction}

Environmental influences on ASB are evident by virtue of the imperfect concordance between monozygotic twins and because environmental conditions influence gene expression (Moffitt 2005). There is replicated evidence that childhood maltreatment is a robust risk factor for conduct problems, ASB, and violence (see review by Glaser 2000). Not only is maltreatment associated with disruptions of the hypothalamic-pituitary-adrenal (HPA) axis, hippocampus, amygdala, cerebellum and left neocortex (Teicher et al. 2003), animal models suggest that early adversity may influence transcription (Champagne and Curley 2005), making it a strong candidate for gene-environment interaction (G x E) studies (Moffitt 2005). Reif et al. (2007) examined 184 adult males and found a significant association between 5-HTTLPR genotype and violence, but only among adults that experienced childhood adversity. Similar results have been reported in other serotonin-related systems, including the monoamine oxidase A (MAOA) gene (Caspi et al. 2002; Kim-Cohen et al. 2006).

Given concerns over statistical power in genetic association studies (i.e., small sample size, small genetic effects, incorrectly assigning a case to a control group, or vice versa) (Hirschhorn et al. 2002), the use of traditional methods to model the probability of group membership may unduly reflect scaling artifacts or extreme samples (Uher and McGuffin 2008). Thus, LCA is superior to traditional categorical methods because LCA classes are unidimensional and they afford greater statistical power, although sample size remains important to LCA (Rindskopf 2009). We are currently unaware of any study that incorporates molecular genetic assays with latent class analysis of ASB. Todd et al. (2005) analyzed a pooled sample of three ADHD studies; two community-based twin samples and a third clinic- and advertisement-based non-twin sibling sample. Using LCA, there was evidence for eight distinct groups based on hyperactive-impulsive, talkative, inattentive and combined symptoms. Significant associations between the 9-repeat allele of the dopamine transporter gene (DAT1) and the 7-repeat allele of the dopamine receptor gene (DRD4) for the severe combined subtype of ADHD were found, suggesting that LCAderived phenotypes were sensitive to genetic effects. Crucially, these genetic effects were not evident when traditional phenotypic definitions were used (e.g., diagnostic groups). Using a large sample of adolescents and young adults who self-reported ASB, we had the following aims: (1) To characterize the latent structure of antisocial youth, separately for boys and girls, using latent class analysis (LCA) and (2) To test the association of 5HTTLPR genotype and maltreatment on latent class membership.

\section{Method}

Participants

The National Longitudinal Study of Adolescent Health (Add Health Harris et al. 2008) ascertained a stratified random sample of youth from U.S. high schools. Details of the study design can be obtained at http://www.cpc.unc.edu/projects/ addhealth. 20,745 adolescents were interviewed at Wave 1 (grades 7-12, ages 12-20 years during the 1994-1995 school year; $47.5 \%$ male). Genetic data were obtained five years later from full siblings and twins only. We analyzed the genetic subsample in Wave 1, which consisted of 2,488 adolescents (mean age $=15.6, \mathrm{SD}=1.6,48 \%$ male). Although adolescents with genetic data were slightly younger $(15.7$ years vs. 15.6 years, respectively) $[F(1,20345)=5.65, p<0.001]$ than adolescents without genetic data, they did not differ significantly with respect to gender $(F(1,20345)=2.81, p=0.09)$ or family income $(F(1,20345)=2.35, p=0.13)$. Finally, although the genetic subsample was ethnically diverse $(57.5 \%$ Caucasian, $14.3 \%$ Hispanic, $18.1 \%$ African-American, $7.4 \%$ Asian, $1.7 \%$ Native American, and $0.9 \%$ "Other"), we emphasize that it is not a nationally representative sample.

\section{Measures}

ASB was ascertained during an in-home interview conducted at Wave 1. Respondents reported the frequency or presence of seven ASB items, including assault with a weapon, vandalism, selling marijuana, breaking and entering, and theft. Because the scaling of items was inconsistent (e.g., frequency counts, categorical), all items were converted to dichotomous data.

Maltreatment was assessed retrospectively during an inhome interview at Wave 3 when subjects were 18-26 years old. Subjects reported the frequency of each of the following events prior to age 12: (1) parents or adult-caregivers not taking care of the respondent's basic needs (e.g., hygiene, food/clothing), (2) been slapped, hit or kicked by parents or adult care-givers, and (3) been touched in a sexual way, forced to touch someone else in a sexual way, or forced to have sexual relations with a parent or adult caregiver. Following expert recommendations (Haberstick et al. 2005), if an event occurred at least once, it was scored as positive. $64.8 \%$ of youth reported no maltreatment history and $35.2 \%$ reported at least one episode. Individuals with genotype data did not differ in maltreatment from individuals without those data $(F(1,14033)=0.04, p=0.84)$.

\section{Genotyping}

Genomic DNA was isolated from buccal cells using standard methods. The primer sequences were: forward, 
5'-GGCGTTGCCGCTCTGAATGC-3' (fluorescently labeled), and reverse, 5'- 46 GAGGGACTGAGCTGGA CAACCAC-3.' These primer sequences yield products of 484 or 528 bp (Heils et al. 1996). The long variant (528 bp) has approximately three times the basal activity of the shorter promoter (484 bp) with the deletion (Lesch et al. 1996). We followed previous strategies (Cicchetti et al. 2007) by comparing three genotypes with the following distributions: SS (20\%), SL (46.5\%), and LL (33.5\%).

\section{Statistical Analyses}

LCA was conducted in Mplus 4.0 (Muthen and Muthen 2006) using the mixture analysis command. To construct the best fitting LCA model, we started with a single class solution and fit successive models with an additional class until the best fitting model was indicated. We report the Bayesian Information Criterion (BIC) value given that it is more robust than other statistical indices (Nylund et al. 2007), as well as the adjusted BIC. To identify the best model fit, we selected the model with the smallest BIC value (Collins et al. 1993). We then added covariates (age, race-ethnicity, family income) and predictors (5-HTTLPR, maltreatment, and their interaction). Models were constructed separately for boys and girls based on the significant difference between sex and latent class membership for the best fitting 2-class solution $\left(\chi^{2}=39.85, d f=\right.$ $1, p<0.01)$. In addition, because the architecture of ASB in girls is not well known (Eley et al. 1999), we used loglinear regression in SAS PROC GENMOD (specifying Poisson distributions) to analyze separate counts of overt and covert ASB to supplement LCA. Finally, to capitalize on the repeated measures design and to identify the latent structure of ASB at different points in development, we utilized the identical data analytic strategies described above at Wave 1 (LCA and log-linear regression of overt and covert ASB separately in boys and girls) again for Wave 2 (1 year follow-up) and Wave 3 (6-7 year follow-up).

\section{Results}

\section{Population Stratification}

We tested the association of genotype and race-ethnicity because allele frequencies for 5-HTTLPR are known to vary by race-ethnicity (Gelernter et al. 1999). 5-HTTLPR genotypes were non-randomly distributed by race-ethnicity in the overall sample $\left(\chi^{2}=2.22, d f=10, p<0.01\right)$, but they were not significantly associated with LCA class membership in males $(\beta=0.44, S E=0.11, p=0.66)$, and females $(\beta=-0.13, S E=0.14, p=0.35)$, thus minimizing the possibility of population stratification (Hutchison et al.
2004). However, because race-ethnicity is associated with ASB (Petras et al. 2004), we included this as a covariate in all models.

\section{Latent Class Models for Girls and Boys}

LCA fit indices for latent class solutions of girls and boys are summarized in Table 1. For girls, a 2-class solution was optimal $(B I C=2,531.73)$. When a third class was added, the BIC and adjusted BIC increased, suggesting a worse model fit. For boys, the 3-class solution was the best fit to the data $(B I C=3,758.79)$. When a 4-class solution was tested, the increase in BIC suggested that the stability of the classes decreased relative to the original 3-class model.

Figure 1 shows the prevalence of group membership and probabilities for girls. Class 1, which accounted for $91 \%$ of girls, was characterized by low probabilities for ASB (No Problems). However, $8.8 \%$ of girls fell into Class 2 (Exclusive Covert), characterized by significantly higher probabilities for endorsing covert forms of ASB [vandalism $(0.79)$, breaking and entering $(0.45)$, and selling marijuana $(0.28)$ ] but low probabilities for overt ASB [pulling a knife or gun on someone $(0.10)$ and shooting or stabbing someone (0.04)]. Unlike boys, there was no evidence of a third class for girls (e.g., mixed covert and overt).

Figure 2 shows the prevalence of class membership and the probability of positively endorsing an item in boys. Nearly $85 \%$ of boys fell into Class 1 , characterized by minor ASB (No Problems). These individuals had low probabilities for endorsing vandalism (0.18), stealing $(<0.01)$, threatening other people with a weapon $(<0.01)$, and pulling a knife or gun on someone $(<0.01)$. Class 2 (Exclusive Covert) consisted of $10.6 \%$ of boys with higher probabilities for covert ASB [vandalism (0.79), stealing (0.34) and selling marijuana $(0.32)$ ] but low probabilities for overt ASB [pull a knife a gun on someone $(<0.01)$, shoot or stab someone $(<0.01)] .4 .5 \%$ of boys fell into Class 3, who had high probabilities for covert and overt ASB (Mixed ASB group): stealing (0.65), selling marijuana (0.52), threatening someone with a weapon (0.64), and pulling a knife or gun on someone (0.89).

Predicting Latent Class Membership

We then modeled the probability of class membership using latent class multinomial regression (Table 2). We first compared the probability of membership in the Exclusive Covert group vs. No Problems group in girls. Although 5HTTLPR genotype was not significantly related to class membership $(\beta=0.62, S E=0.52, p=0.24)$, there were significant effects for maltreatment $(\beta=2.49, S E=1.05$, $p=0.02)$ and its interaction with 5-HTTLPR genotype $(\beta=$ -1.98, $S E=0.77, p<0.01$ ) in predicting membership in the 
Table 1 Fit Indices for LCA Models with 1-6 Classes

\begin{tabular}{llllr}
\hline & Number of Classes & BIC & Adjusted BIC & Free Parameters \\
\hline Boys $(n=1,054)$ & 1 & $3,758.79$ & $3,736.56$ & 7 \\
& 2 & $3,276.99$ & $3,229.35$ & 15 \\
& $\mathbf{3}$ & $\mathbf{3 , 2 7 4 . 8 8}$ & $\mathbf{3 , 2 0 1 . 8 3}$ & $\mathbf{2 3}$ \\
& 4 & $3,299.64$ & $3,201.18$ & 31 \\
Girls $(n=1,144)$ & 5 & $3,347.52$ & $3,223.65$ & 39 \\
& 6 & $3,374.91$ & $3,225.63$ & 47 \\
& 1 & $2,751.47$ & $2,729.23$ & 7 \\
& $\mathbf{2}$ & $\mathbf{2 , 5 3 1 . 7 3}$ & $\mathbf{2 , 4 4 4 . 0 9}$ & $\mathbf{1 5}$ \\
& 3 & $2,532.48$ & $2,459.42$ & 23 \\
& 4 & $2,558.33$ & $2,459.86$ & 31 \\
& 5 & $2,604.67$ & $2,480.79$ & 39 \\
& 6 & $2,643.88$ & $2,494.59$ & 47 \\
\hline
\end{tabular}

Bold indicates best fitting model BIC = Bayesian information criterion respectively). In addition, we note that when the interaction terms were not included in the models, the effects for 5HTTLPR and maltreatment were not significant for boys or girls (data available upon request).

Finally, because passive gene-environment correlation (rGE) can complicate the interpretation of G x E (Jaffee and Price 2007), we explored whether genotype was significantly associated with maltreatment. After controlling for age, race-ethnicity, family income and sex, maltreatment was unrelated with 5-HTTLPR genotype $(r=-0.007, d f=$ $1,803, p=0.77)$, thereby reducing concerns that passive rGE confounded the observed interaction.

Predicting Counts of ASB

To provide an additional characterization of variability in ASB, we analyzed counts of overt and covert ASB at Wave 1 (i.e., sum of positive endorsements for each item) using log-linear regression (SAS PROC GENMOD) based
Fig. 1 Latent class membership probabilities for girls

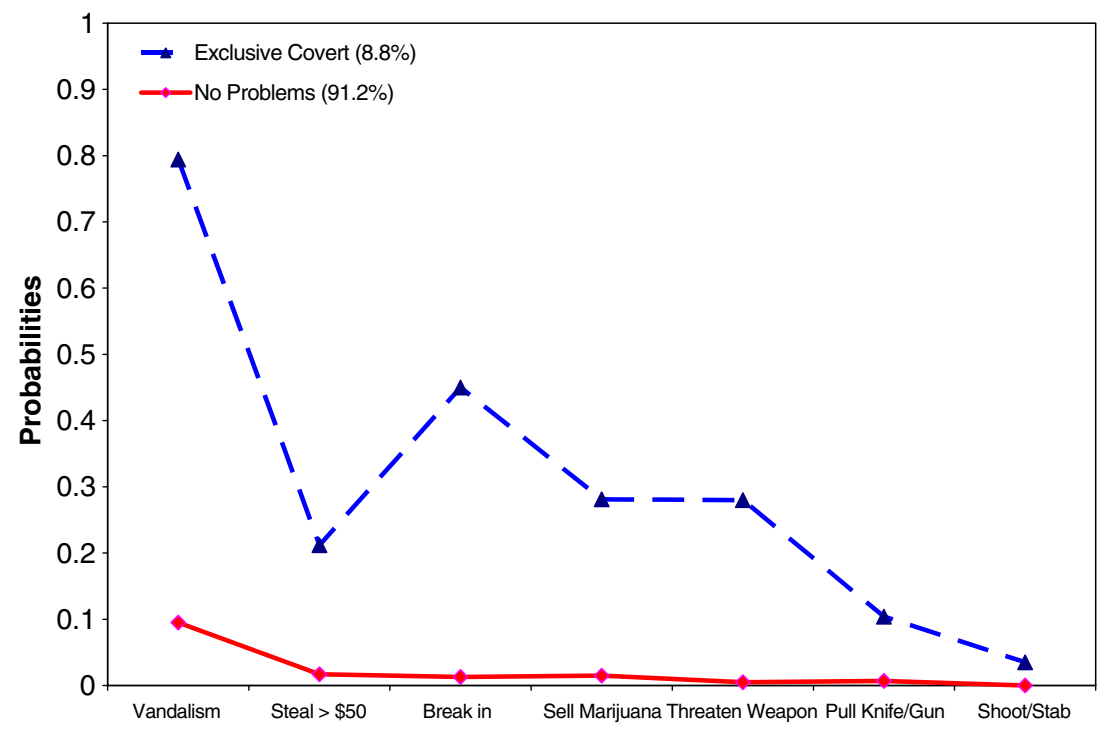


Fig. 2 Latent class membership probabilities for boys

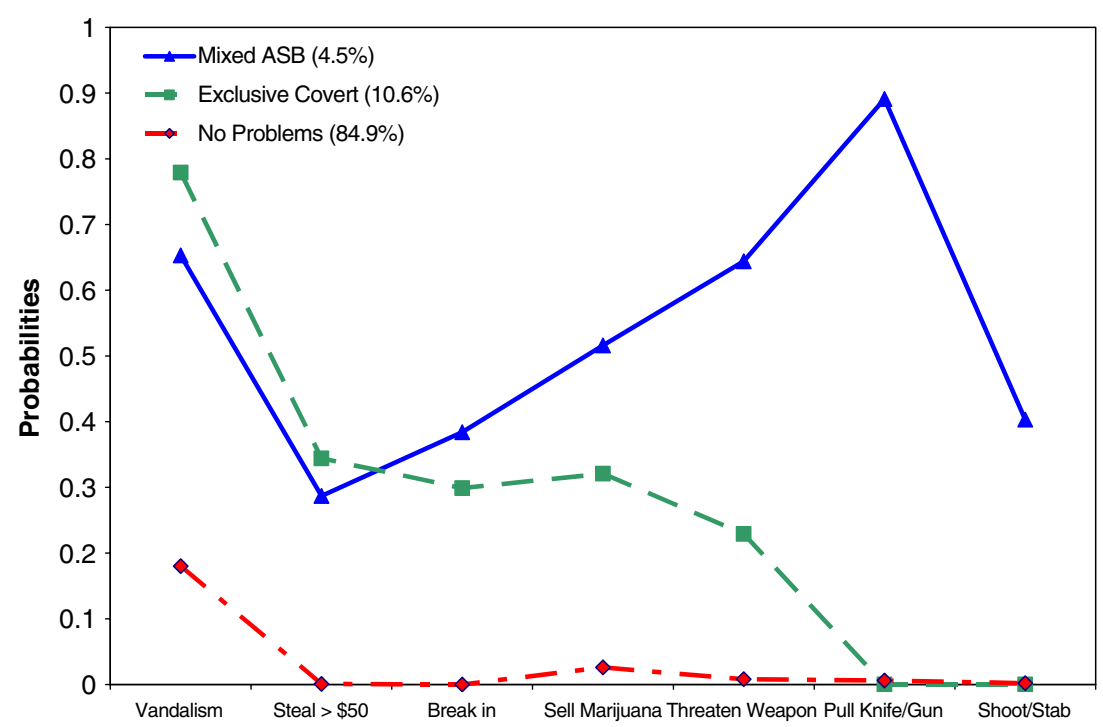

on 5-HTTLPR genotype, maltreatment, and their interaction (controlling for age, race-ethnicity and family income). Among boys, genotype and maltreatment were not significantly related to covert ASB $(\beta=0.12, S E=0.40, p=0.76$ and $\beta=-0.70, S E=0.56, p=0.21$, respectively) and overt $\operatorname{ASB}(\beta=0.08, S E=0.59, p=0.88$ and $\beta=-0.20, S E=0.96$, $p=0.84$, respectively). In addition, the interaction between genotype and maltreatment was not significantly predictive of covert and overt $\operatorname{ASB}(\beta=-0.03, S E=0.04, p=0.94$ and $\beta=-0.37, S E=0.76, p=0.62$, respectively). However, in girls, there was a significant effect for genotype for covert ASB $(\beta=0.56, S E=0.25, p=0.02)$, but not for maltreatment $(\beta=0.62, S E=0.41, p=0.13)$. The interaction between genotype and maltreatment was also significant for covert ASB $(\beta=-0.54, S E=0.27, p=0.05)$. For overt ASB in girls, the effects for genotype and maltreatment were not significant $(\beta=0.81, S E=0.58, p=0.16$ and $\beta=0.36, S E=1.12, p$ $=0.75)$, but their interaction was significant $(\beta=-1.82, S E=$ $0.82, p<0.05$ ). Post-hoc probing of the interactions suggested that the association between 5-HTTLPR genotype and covert ASB was only significant for girls with a maltreatment history $(\beta=0.50, S E=0.22, p=0.02)$, although the same simple effect was not evident for overt ASB $(\beta=$ $0.78, S E=0.58, p=0.17$ ). For girls that were not maltreated, the relationship between 5-HTTLPR and ASB was not significant for covert $\mathrm{ASB}(\beta=0.02, S E=0.27, p=0.93)$ and overt ASB $(\beta=-1.11, S E=0.62, p=0.07)$.

We then extended the same analytic approach (log-linear regression with identical covariates) to counts of covert and overt ASB at Wave 2 (1 year follow-up) and Wave 3 (67 year follow-up) separately for boys and girls. For boys at Wave 2, 5-HTTLPR and maltreatment were unrelated to covert ASB $(\beta=-0.04, S E=0.22, p=0.85$ and $\beta=-0.26$, $S E=0.56, p=0.64$, respectively) and overt ASB $(\beta=-0.37$, $S E=0.44, p=0.40$ and $\beta=-0.77, S E=0.89, p=0.38$, respectively). Similarly, for girls at Wave 2, 5-HTTLPR and maltreatment were not significant predictors of covert $\operatorname{ASB}(\beta=-0.38, S E=0.27, p=0.16$ and $\beta=0.25, S E=0.56$, $p=0.65$, respectively) and overt $\operatorname{ASB}(\beta=0.45, S E=1.05$, $p=0.67$ and $\beta=0.68, S E=1.77, p=0.70$, respectively). Moreover, genotype $\mathrm{x}$ maltreatment interaction was not significant for overt ASB $(\beta=0.87, S E=1.18, p=0.46$ and $\beta=-0.90, S E=1.67, p=0.59$ for boys and girls, respectively) and covert ASB $(\beta=-0.01, S E=0.51, p=0.98$ and $\beta=-0.37, S E=0.45, p=0.42$, for boys and girls, respectively). For boys at Wave 3, maltreatment significantly predicted covert ASB $(\beta=-1.36, S E=0.58, p<0.05)$, but 5 HTTLPR did not $(\beta=-0.25, S E=0.31, p=0.43)$. However,
Table 2 Latent Class Multinomial Logistic Regression Model for Girls

Covariates $=$ age, race-ethnicity, and family income; 5-HTTLPR = serotonin transporter genotype (SS, SL, or LL); $B=$ parameter estimate (in logits); $S E=$ standard error; OR $=$ odds ratio

\begin{tabular}{lcccc}
\hline Variables & \multicolumn{4}{l}{ Exclusive Covert vs. No Problems } \\
\cline { 2 - 5 } & \multicolumn{1}{l}{$B$} & $S E$ & OR (95\% CI) & $p$ \\
\hline Age & -0.06 & 0.11 & $1.00(0.77-1.22)$ & 0.59 \\
Race-Ethnicity & 0.25 & 0.14 & $1.28(1.01-1.55)$ & 0.08 \\
Family Income & 0.00 & 0.00 & $1.00(1.00-1.00)$ & 0.58 \\
5-HTTLPR & 0.62 & 0.52 & $1.85(0.82-2.87)$ & 0.24 \\
Maltreatment & 2.49 & 1.05 & $12.04(9.99-14.09)$ & 0.02 \\
Maltreatment x 5-HTTLPR & -1.98 & 0.77 & $7.24(5.84-8.84)$ & 0.00 \\
\hline
\end{tabular}


Table 3 Latent Class Multinomial Logistic Regression Models for Boys

\begin{tabular}{|c|c|c|c|c|c|c|c|c|}
\hline \multirow[t]{2}{*}{ Variables } & \multicolumn{4}{|c|}{ Mixed ASB vs. No Problems } & \multicolumn{4}{|c|}{ Exclusive Covert vs. No Problems } \\
\hline & $B$ & $S E$ & OR $(95 \% \mathrm{CI})$ & $p$ & $B$ & $S E$ & OR $(95 \% \mathrm{CI})$ & $p$ \\
\hline Age & -0.14 & 0.19 & $1.15(0.78-1.52)$ & 0.48 & -0.24 & 0.27 & $1.27(0.74-1.80)$ & 0.37 \\
\hline Race-Ethnicity & -0.26 & 0.11 & $1.30(1.08-1.52)$ & 0.02 & 0.13 & 0.14 & $1.14(0.77-1.51)$ & 0.37 \\
\hline Family Income & 0.02 & 0.02 & $1.02(0.98-1.06)$ & 0.27 & 0.03 & 0.02 & $1.03(0.97-1.09)$ & 0.08 \\
\hline 5-HTTLPR & -0.37 & 0.51 & $1.47(0.47-2.47)$ & 0.47 & -0.01 & 0.57 & $1.00(0.00-2.33)$ & 0.99 \\
\hline Maltreatment & 0.39 & 0.92 & $1.44(0.00-3.24)$ & 0.67 & -0.24 & 1.25 & $1.27(0.00-3.72)$ & 0.85 \\
\hline Maltreatment x 5-HTTLPR & 0.67 & 1.27 & $1.96(0.00-4.45)$ & 0.60 & 1.76 & 1.58 & $5.81(2.71-8.91)$ & 0.27 \\
\hline
\end{tabular}

Covariates $=$ age, race-ethnicity, and family income; 5 -HTTLPR $=$ serotonin transporter genotype (SS, SL, or LL); $B=$ parameter estimate (in logits); $S E=$ standard error; $\mathrm{OR}=$ odds ratio

5-HTTLPR and maltreatment were unrelated to overt ASB $(\beta=0.03, S E=0.02, p=0.08$ and $\beta=-0.01, S E=0.03, p=$ 0.62 , respectively). For girls at Wave 3 , there was also a significant effect for maltreatment $(\beta=-1.41, S E=0.73, p$ $=0.05)$, but not for 5-HTTLPR $(\beta=-0.57, S E=0.37, p=$ $0.13)$ in predicting covert ASB whereas their effects were not significant for overt ASB $(\beta=-0.01, S E=0.01, p=0.29$ and $\beta=-0.03, S E=0.02, p=0.31$ for maltreatment and genotype, respectively). The genotype $\mathrm{x}$ maltreatment interaction was not significant for boys and girls for overt $\operatorname{ASB}(\beta=-0.89, S E=1.75, p=0.61$ and $\beta=0.02, S E=0.02$, $p=0.31$, respectively) and covert $\operatorname{ASB}(\beta=1.01, S E=0.55$, $p=0.07$, and $\beta=0.71, S E=0.72, p=0.32$, respectively).

\section{Latent Structure of ASB Across Development}

To investigate the structure of ASB at additional developmental periods, we conducted LCA for ASB at Wave 2 and Wave 3. LCA of ASB data at Wave 2 revealed that a 2-class solution optimally characterized boys $(\mathrm{BIC}=2,893.70)$ and girls $(\mathrm{BIC}=2,030.50)$. Relative to Wave $1, \mathrm{ASB}$ in boys at Wave 2 consisted of Mixed ASB and No ASB groups only (LCA no longer derived an Exclusive Covert ASB class). For girls, the latent class structure at Wave 2 approximated their structure at Wave 1 (Exclusive Covert and No ASB groups). At Wave 3, only a single latent class was detected for boys and girls.

\section{Discussion}

To improve traction on the underlying structure of ASB, we used latent class analysis (LCA) to empirically derive groups of adolescents based on their self-reported ASB. Our analyses yielded several key findings: (1) Boys and girls differed in the number of empirically distinct groups, with boys being optimally characterized by three classes (No Problems, Exclusive Covert, and Mixed Covert and
Overt) whereas girls consisted of two classes (No Problems, Exclusive Covert); (2) Maltreatment was significantly related to the likelihood of Exclusive Covert ASB class membership for girls, but not for boys; and (3) In girls, the influence of maltreatment and Exclusive Covert ASB status was moderated by 5-HTTLPR genotype. Among maltreated girls, the SS genotype conferred a 12 times increase in the odds of being in the Exclusive Covert group than in the No Problems group. No significant interaction was found for boys. Furthermore, genotype and maltreatment were not significantly related with age, sex, family income, and raceethnicity controlled, thereby reducing the likelihood of passive rGE. Finally, when ASB was assessed separately at each wave across 6-7 years of development, we found that the number of ASB classes derived decreased over time for girls and boys. At Wave 2, boys and girls were similarly characterized by two latent classes: for boys, Exclusive Covert was no longer identified by LCA whereas the structure of ASB in girls was similar to Wave 1. However, by Wave 3, a single class solution characterized ASB in boys and girls. The results suggest that overt and covert forms of ASB are distinct in boys, but covert ASB prevails in girls. These findings extend earlier factor-analytic studies by Loeber and Schmaling (1985) and Frick et al. (1993) by demonstrating that covert and overt forms of ASB are not mutually exclusive, as overtly aggressive youth often commit more non-violent offenses than exclusively nonviolent offenders (Farrington 1998). Specifically for boys, violent offenders were more likely to participate in covert ASB whereas covert offenders showed more specificity in their offending. This pattern may be due to stronger genetic influences for overt/aggressive ASB than covert/non-aggressive ASB (Burt 2009). Moreover, there is considerable genetic and phenotypic overlap between overt and covert ASB (Willoughby et al. 2001), although there are also unique genetic influences. Some genes may be specific to overt ASB, although these investigations are still in their infancy (Burt 2009). Our findings on the structural changes 
in ASB from adolescence to adulthood reflect prevailing theories about the reliable decrease in the frequency of ASB and the number of offenders from adolescence to early adulthood (Moffitt 1993). Alternatively, the processes underlying adolescent ASB may be expressed in different behaviors not captured by this particular assessment. For example, substance use disorders may be more prominent in early adulthood relative to developmentally-sensitive forms of ASB and delinquency (Glantz et al. 2009).

For girls, ASB was exclusively covert in nature, with no empirically-derived group of overt offenders. In this large sample of girls, the absence of an overt class of ASB is consistent with previous reviews (Keenan et al. 1999; Eley et al. 1999; Archer 2004) that contend adolescent girls engage disproportionately in non-aggressive ASB (Crick and Zahn-Wexler 2003). Unfortunately, data on indirect aggression were unavailable in this sample. Relational aggression may be crucial to understand ASB in girls. Crick and Zahn-Wexler (2003) found that $80 \%$ of girls would not have been classified as "aggressive" without including indirect aggression. Sex differences in empathy may also contribute to the salience of covert ASB in girls (Archer 2004; Keenan et al. 1999). By early adolescence, girls express more empathy, guilt, and rumination than boys following a conflict and may be less likely to use physical aggression (Keenan et al. 1999). However, despite being less overtly aggressive than boys, antisocial girls still experience severe long-term consequences in adulthood, including significant mental health, physical health, and economic problems (Odgers et al. 2008), reflecting a greater need to understand mediators of outcome among covertly aggressive girls.

Importantly, we found a significant interaction between maltreatment and 5-HTTLPR genotype in predicting membership in the Exclusive Covert ASB group for girls, but not for boys. In the presence of maltreatment, the SS genotype was robustly related to ASB, with a 12 fold increase in the odds of being in the Exclusive Covert group than in the No Problems group. The $\mathrm{S}$ allele has been consistently implicated in previous studies of ASB (Uher and McGuffin 2008; Haberstick et al. 2006; Liao et al. 2004), given its association with decreased 5-HT transporter functioning (Hariri et al. 2002). However, the effect of decreased 5-HT transporter functioning on cortical 5-HT and subsequent ASB is not well understood (Beitchman et al. 2006; Carrillo et al. 2009). Depleted 5-HT transporter may be a strong risk factor for ASB in girls and 5-HTTLPR genotype may differentially increase susceptibility to maltreatment in girls than in boys. This may reflect heightened sensitivity to environmental stressors. For example, relative to boys, girls react more negatively to family disruptions, peer problems, and stress perception (Crick and Zahn-Wexler 2003; Keenan and Shaw 1997;
Keenan et al. 1999). In the context of peer problems, for example, girls gain less from engaging in overt ASB, relative to boys, because girls who engage in overtly aggressive behaviors are often more rejected than their male counterparts. Instead, they are more likely to gain peer support by spreading rumors or lies, ostracizing others, and engaging in other covert ASB (Keenan et al. 1999). Emerging work also suggests that the $\mathrm{S}$ allele enhances sensitivity to environmental conditions, both in the presence of environmentally negative and nurturing conditions (Uher and McGuffin 2008; Belsky et al. 2009). For example, SS homozygotes had the highest risk for depression in combination with early childhood adversity, but they also had the fewest symptoms of depression when they were exposed to a positive rearing environment (Taylor et al. 2006). Thus, putative risk genotypes may simultaneously increase responsiveness to enriching environments and perhaps to intervention as well. This theory has yet to be thoroughly interrogated for ASB and other phenotypes. Consequently, we await further tests that genes concurrently influence responsiveness to environmental adversity and nurturance.

Although our LCA uncovered distinct latent classes for ASB in boys and girls, we supplemented the LCA approach with log-linear regression models using counts of overt and covert ASB. Notably, even when count data were used to characterize ASB in girls at Wave 1, there was a significant main effect for 5-HTTLPR genotype for covert ASB and a significant interaction between 5-HTTLPR genotype and maltreatment for both overt and covert ASB. Crucially, LCA and log-linear models both indicated that genotype and covert ASB at Wave 1 was associated only in maltreated girls. However, to more thoroughly assess potential for $G \times E$ effects across development, we constructed identical log-linear models of overt and covert ASB at Wave 2 and Wave 3 using maltreatment, genotype, and their interaction. Unlike Wave 1, there was no effect of maltreatment, genotype, or their interaction on overt and covert ASB at Wave 2. Similarly, at Wave 3, there was only evidence of maltreatment effects on covert ASB in boys and girls, but no evidence of genotype or G x E effects. Thus, the G x E effects on ASB was limited to Wave 1 when participants were 12-20 years. Finally, our LCA at Wave 3 revealed no distinguishable latent classes for ASB for either sex, suggesting that a distinction between covert and overt ASB may not be empirically warranted later in development (e.g., adulthood).

We emphasize several important limitations to our study. First, ASB was ascertained through self-report, which may underestimate ASB (Huizinga and Elliot 1986). Youth with severe ASB are known to be elusive in some studies because they are uncooperative and absent from school/ home (Farrington 1998). Additional informants and sources 
of ASB (e.g., official records) may improve measurement accuracy (Caspi et al. 2002; Jaffee et al. 2004). In addition, childhood maltreatment was assessed retrospectively, which may be influenced by mood states or psychopathology, inaccurate recall, and/or lack of trust. However, Smith et al. (2008) compared self-reported maltreatment with official state records of maltreatment and found that both methods predicted antisocial outcomes in adolescence/adulthood, but combining the measures did not improve predictive validity. Second, to correct discrepancies in item response types (e.g., count vs. dichotomous), we dichotomized all responses. This may have reduced variance and statistical power. However, Farrington and Loeber (2000) contend that dichotomization does not greatly affect the strength of associations. Third, recent findings suggest that the $\mathrm{Lg}$ allele may be transcriptionally similar to the $\mathrm{S}$ allele and that both "low expressing variants" are related to childhood aggression (Beitchman et al. 2006). However, the Lg allele was not genotyped in this sample. Fourth, our analysis of sex differences in the $\mathrm{G} \times \mathrm{E}$ effect for ASB was not formally indicated by a significant interaction. We conducted a priori analyses separately in boys and girls based on the number of different classes (3 and 2, respectively) indicated by LCA and a significant difference in the distribution of sex in the best fitting 2-class model. Fifth, although latent transition analysis (LTA) is appropriate for ASB trajectories, LTA necessitates that items and classes are factorially invariant across each assessment (Cumsille et al. 2002). One option to achieve factorial invariance is to constrain responses probabilities to specific items at each wave (Reboussin et al. 2007), thereby ensuring class stability. However, given the strong effect of age on ASB (overall and in this study) and the factorial variability across the three waves in boys and girls, this approach was prohibitive. Nevertheless, we cannot address whether an interaction between maltreatment and 5-HTTLPR genotype influences class membership trajectories. Finally, we emphasize that the Gx E effects on ASB were specific to Wave 1, suggesting that $\mathrm{G} \times \mathrm{E}$ may be developmentallyspecific. For example, age moderated genetic and environmental influences in a meta-analysis of ASB (Rhee and Waldman 2002). Thus, given the centrality of environmental influences on gene expression, $\mathrm{G} \times \mathrm{E}$ effects must be interpreted in the context of ongoing developmental influences.

In summary, LCA derived distinct groups of ASB offenders in boys and girls (three and two classes, respectively). Consistent with previous studies (Loeber and Schmaling 1985; Frick et al. 1993), adolescent boys were best characterized by a No Problem, Exclusive Covert, and Mixed Overt and Covert group of offenders. However, among girls, a 2-class model was indicated, consisting of No Problem and Exclusive Covert groups only. We also uncovered evidence of $\mathrm{G}$ x $\mathrm{E}$ between maltreatment and 5-HTTLPR, but only for girls. Specifically, maltreated girls with the SS genotype of the 5HTTLPR gene were more likely to be in the Exclusive Covert group than girls with different genotypes. We anticipate that integrated models of risk, incorporating genetic and environmental constructs with empiricallyderived groups of youth, will facilitate the development and implementation of targeted interventions to reduce the considerable burden associated with significant ASB.

Acknowledgements This research uses data from the National Longitudinal Study of Adolescent Health (Add Health), a program project designed by J. Richard Udry, Peter S. Bearman, and Kathleen Mullan Harris and funded by the National Institute of Child Health and Human Development Grant PO1-HD31921 with cooperative funding from 17 other agencies.

Open Access This article is distributed under the terms of the Creative Commons Attribution Noncommercial License which permits any noncommercial use, distribution, and reproduction in any medium, provided the original author(s) and source are credited.

\section{References}

Aguilar, B., Sroufe, L. A., Egeland, B., \& Carlson, E. (2000). Distinguishing the early-onset/persistent and adolescence-onset antisocial behavior types: from birth to 16 years. Development and Psychopathology, 12(2), 109-132.

Archer, J. (2004). Sex differences in aggression in real-world settings: a meta-analytic review. Review of General Psychology, 8(4), 291-322.

Barker, E. D., Larsson, H., Viding, E., Maughan, B., Rijsdijk, F., Fontaine, N., et al. (2009). Common genetic but specific environmental influences for aggressive and deceitful behaviors in preadolescent males. Journal of Psychopathology and Behavioral Assessment, 3, 299-308.

Belsky, J., Jonassaint, C., Pluess, M., Stanton, M., Brummett, B., \& Williams, R. (2009). Vulnerability genes or plasticity genes? Molecular Psychiatry, 14(8), 746-754.

Bergman, L. R., \& Magnusson, D. (1997). A person-oriented approach in research on developmental psychopathology. Developmental Psychopathology, 9(2), 291-319.

Beitchman, J. H., Baldassarra, L., Mik, H., De Luca, V., King, N., \& Kennedy, J. L. (2006). Serotonin transporter polymorphisms and persistent pervasive childhood aggression. American Journal of Psychiatry, 163, 1103-1105.

Brown, G. L., Goodwin, F. K., Ballenger, J. C., Goyer, P. F., \& Major, L. F. (1979). Aggression in humans correlates with cerebrospinal fluid amine metabolites. Psychiatry Research, 1(2), 131-139.

Burt, S. A. (2009). Are there meaningful etiological differences within antisocial behavior? Results of a meta-analysis. Clinical Psychology Review, 29(2), 163-178.

Burt, S. A., Mikolajewski, A. J., \& Larson, C. L. (2009). Do aggression and rule-breaking have difference interpersonal correlates? A study of antisocial behavior subtypes, negative affect, and hostile perception of others. Aggressive Behavior, 35, 453-461.

Carrillo, M., Ricci, L. A., Coppersmith, G. A., \& Melloni, R. H., Jr. (2009). The effect of increased serotonergic neurotransmission on aggression: a critical meta-analytical review of preclinical studies. Psychopharmacology, 205(3), 349-368. 
Caspi, A., McClay, J., Moffitt, T. E., Mill, J., Martin, J., Craig, I. W., et al. (2002). Role of genotype in the cycle of violence in maltreated children. Science, 297(5582), 851-854.

Champagne, F. A., \& Curley, J. P. (2005). How social experiences influence the brain. Current Opinion in Neurobiology, 15(6), 704-709.

Cicchetti, D., Rogosch, F. A., \& Sturge-Apple, M. L. (2007). Interactions of child maltreatment and serotonin transporter and monoamine oxidase A polymorphisms: depressive symptomatology among adolescents from low socioeconomic status backgrounds. Development and Psychopathology, 19(4), 1161-1180.

Cohen, P., Cohen, J., Velez, S. C. N., Hartmark, C., Johnson, J., Rojas, M., et al. (1993). An epidemiological study of disorders in late childhood and adolescence-I. Age- and gender-specific prevalence. Journal of Child Psychology and Psychiatry and Allied Disciplines, 34, 851-867.

Collins, L. M., Fidler, P. L., Wugalter, S. E., \& Long, J. D. (1993). Goodness-of-fit testing for latent class models. Multivariate Behavioral Research, 28(3), 375-389.

Crick, N. R., \& Zahn-Wexler, C. (2003). The development of psychopathology in females and males: current progress and future challenges. Development and Psychopathology, 15(3), 719-742.

Cumsille, P., Darling, N., Flaherty, B., \& Loreto Martínez, M. (2002). Heterogeneity and change in the patterning of adolescents' perceptions of the legitimacy of parental authority: a latent transition model. Child Development, 80(2), 418-432.

De Nijs, P. F. A., van Lier, P. A. C., Verhulst, F. C., \& Ferdinand, R. F. (2007). Classes of disruptive behavior problems in referred adolescents. Psychopathology, 40(6), 440-445.

Dishion, T. J., \& Patterson, G. R. (2006). The development and ecology of antisocial behavior in children and adolescents. In D. Cicchetti \& D. J. Cohen (Eds.), Developmental psychopathology (2nd ed., Vol. 3, pp. 503-541). Hoboken: Wiley.

Eley, T. C., Lichtenstein, P., \& Stevenson, J. (1999). Sex differences in the etiology of aggressive and nonaggressive antisocial behavior: results from two twin studies. Child Development, 70(1), 155-168.

Farrington, D. P. (1995). The development of offending and antisocial behaviour from childhood: key findings from the Cambridge Study in Delinquent Development. Journal of Child Psychology and Psychiatry, 36, 929-964.

Farrington, D. P. (1998). Predictors, causes, and correlates of male youth violence. Crime and Justice, 24, 421-475.

Farrington, D. P., \& Loeber, R. (2000). Some benefits of dichotomization in psychiatric and criminological research. Criminal Behaviour and Mental Health, 10, 100-122.

Fergusson, D. M., Horwood, L. J., \& Ridder, E. M. (2005). Show me the child at seven: the consequences of conduct problems in childhood for psychosocial functioning in adulthood. Journal of Child Psychology and Psychiatry, 46(8), 837-849.

Foster, E. M., \& Jones, D. E. (2005). The high cost of aggression: public expenditures resulting from conduct disorder. American Journal of Public Health, 95(10), 1767-1772.

Frick, P. J., Lahey, B. B., Loeber, R., Tannenbaum, L., Van Horn, Y., Christ, M. A. G., et al. (1993). Oppositional defiant disorder and conduct disorder: a meta-analytic review of factor analyses and cross-validation in a clinic sample. Clinical Psychology Review, 13(4), 319-340.

Frick, P. J., Cornell, A. H., Barry, C. T., Bodin, S. D., \& Dane, H. E. (2003). Callous-unemotional traits and conduct problems in the prediction of conduct problem severity, aggression, and selfreport of delinquency. Journal of Abnormal Child Psychology, 31 (4), 457-470.

Gelernter, J., Cubells, J. F., Kidd, J. R., Pakstis, A. J., \& Kidd, K. K. (1999). Population studies of polymorphisms of the serotonin transporter protein gene. American Journal of Medical Genetics, $88(1), 61-66$.
Gibbons, J. L., Barr, G. A., Bridger, W. H., \& Leibowitz, S. F. (1997). Manipulations of dietary tryptophan: effects on mouse killing and brain serotonin in the rat. Brain Research, 169(1), 139-153.

Glantz, M. D., Anthony, J. C., Berglund, P. A., Degenhardt, L., Dierker, L., Kalaydjian, A., et al. (2009). Mental disorders as risk factors for later substance dependence: estimates of optimal prevention and treatment benefits. Psychological Medicine, 39, $1365-1377$.

Glaser, D. (2000). Child abuse and neglect and the brain-a review. Journal of Child Psychology and Psychiatry, 41(1), 97-116.

Goodman, S. H., Lahey, B. B., Fielding, B., Dulcan, M., Narrow, W., \& Regier, D. (1997). Representativeness of clinical samples of youths with mental disorders: a preliminary population-based study. Journal of Abnormal Psychology, 106, 3-14.

Haberstick, B. C., Lessem, J. M., Hopfer, C. J., Smolen, A., Ehringer, M. A., Timberlake, D., et al. (2005). Monoamine oxidase A (MAOA) and antisocial behaviors in the presence of childhood and adolescent maltreatment. American Journal of Medical Genetics Part B: Neuropsychiatric Genetics, 135B(1), $59-64$.

Haberstick, B. C., Smolen, A., \& Hewitt, J. K. (2006). Family-based association test of the 5HTTLPR and aggressive behavior in a general population sample of children. Biological Psychiatry, 59 (9), 836-843.

Hariri, A. R., Mattay, V. S., Tessitore, A., Kolachana, B., Fera, F., Goldman, D., et al. (2002). Serotonin transporter genetic variation and the response of the human amygdala. Science, 297(5580), 400-403.

Heils, A., Teufel, A., Petri, S., Stöber, G., Riederer, P., Bengel, D., et al. (1996). Allelic variation of human serotonin transporter gene expression. Journal of Neurochemistry, 66(6), 2621-2624.

Higley, J. D., Mehlman, P. T., Poland, R. E., Taub, D. M., Vickers, J., Suomi, S. J., et al. (1996). CSF testosterone and 5-HIAA correlate with different types of aggressive behaviors. Biological Psychiatry, 40(11), 1067-1082.

Hipwell, A. E., Loeber, R., Stouthamer-Loeber, M., Keenan, K., White, H. R., \& Kroneman, L. (2002). Characteristics of girls with early onset disruptive and antisocial behavior. Criminal Behavior and Mental Health, 12, 99-118.

Hirschhorn, J. N., Lohmueller, K., Byrne, E., \& Hirschhorn, K. (2002). A comprehensive review of genetic association studies. Genetics in Medicine, 4(2), 45-61.

Holmes, A., Murphy, D. L., \& Crawley, J. N. (2002). Reduced aggression in mice lacking the serotonin transporter. Psychopharmacology, 161(2), 160-167.

Huizinga, D., \& Elliot, D. S. (1986). Reassessing the reliability and validity of self-report delinquency measures. Journal of Quantitative Criminology, 2(4), 293-327.

Hutchison, K. E., Stallings, M., McGeary, J. M., \& Bryan, A. (2004). Population stratification in the case-control design: fatal threat or red herring? Psychological Bulletin, 130(1), 66-79.

Jaffee, S. R., Caspi, A., Moffitt, T. E., \& Taylor, A. (2004). Physical maltreatment victim to antisocial child: evidence of an environmentally mediated process. Journal of Abnormal Psychology, 113 (1), 44-55.

Jaffee, S. R., \& Price, T. S. (2007). Gene-environment correlations: a review of the evidence and implications for prevention of mental illness. Molecular Psychiatry, 12(5), 432-442.

Kazdin, A. E., Whitley, M., \& Marciano, P. L. (2006). Childtherapist and parent - therapist alliance and therapeutic change in the treatment of children referred for oppositional, aggressive, and antisocial behavior. Journal of Child Psychology and Psychiatry, 47(5), 436-445.

Keenan, K., \& Shaw, D. (1997). Developmental and social influences on young girls' early problem behavior. Psychological Bulletin, $121(1), 95-113$. 
Keenan, K., Loeber, R., \& Green, S. (1999). Conduct disorder in girls: a review of the literature. Clinical Child and Family Psychology Review, 2(1), 3-19.

Kim-Cohen, J., Caspi, A., Taylor, A., Williams, B., Newcombe, R., Craig, I. W., et al. (2006). MAOA, maltreatment, and geneenvironment interaction predicting children's mental health: new evidence and a meta-analysis. Molecular Psychiatry, 11(10), 903-913.

Lahey, B. B., Waldman, I. D., \& McBurnett, K. (1999). Annotation: the development of antisocial behavior: an integrative causal model. Journal of Child Psychology and Psychiatry, and Allied Disciplines, 40(5), 669-682.

Lavigne, J. V., LeBailly, S. A., Hopkins, J., Gouze, K. R., \& Binns, H. J. (2009). The prevalence of ADHD, ODD, depression, and anxiety in a community sample of 4-year-olds. Journal of Clinical Child and Adolescent Psychology, 38(3), 315-338.

LeDoux, J. E. (2000). Emotion circuits in the brain. Annual Review of Neuroscience, 23, 155-184.

Lee, S. S., \& Hinshaw, S. P. (2004). Severity of adolescent delinquency among boys with and without attention deficit hyperactivity disorder: predictions from early antisocial behavior and peer status. Journal of Clinical Child and Adolescent Psychology, 33(4), 705-716.

Lee, S. S., \& Hinshaw, S. P. (2006). Predictors of adolescent functioning in girls with attention deficit hyperactivity disorder (ADHD): the role of childhood ADHD, conduct problems, and peer status. Journal of Clinical Child and Adolescent Psychology, 35(3), 356-368.

Lee, K., Baillargeon, R. H., Vermunt, J. K., Wu, H., \& Tremblay, R. E. (2007). Age differences in the prevalence of physical aggression among 5-11-year-old Canadian boys and girls. Aggressive Behavior, 33(1), 26-37.

Lesch, K. P., Bengel, D., Heils, A., Sabol, S. Z., Greenberg, B. D., Petri, S., et al. (1996). Association of anxiety-related traits with a polymorphism in the serotonin transporter gene regulatory region. Science, 274(5292), 1527-1531.

Levin, A. (2008). Subthreshold symptoms: where do they lead? Psychiatric News, 43(23), 14-34.

Liao, D. L., Hong, C. J., Shih, H. L., \& Tsai, S. J. (2004). Possible association between serotonin transporter promoter region polymorphism and extremely violent crime in Chinese males. Neuropsychobiology, 50(4), 284-287.

Loeber, R., \& Keenan, K. (1994). Interaction between conduct disorder and its comorbid conditions: effects of age and gender. Clinical Psychology Review, 14(6), 497-523.

Loeber, R., \& Schmaling, K. B. (1985). Empirical evidence for overt and covert patterns of antisocial conduct problems: a metaanalysis. Journal of Abnormal Child Psychology, 13(2), 337-353.

Loeber, R., \& Stouthamer-Loeber, M. (1998). Development of juvenile aggression and violence: some common misconceptions and controversies. American Psychologist, 53(2), 242-259.

Magidson, J., \& Vermunt, J. K. (2004). Latent class models. In D. Kaplan (Ed.), The sage handbook of quantitative methodology for the social sciences (pp. 175-198). Thousand Oakes: Sage.

McCutcheon, A. L. (1987). Sexual morality, pro-life values, and attitudes toward abortion: a simultaneous latent structure analysis for 1978-1983. Sociological Methods \& Research, 16(2), 256275.

Moffitt, T. E. (1993). Adolescence-limited and life-course-persistent antisocial behavior: a developmental taxonomy. Psychological Review, 100(4), 674-701.

Moffitt, T. E. (2005). Genetic and environmental influences on antisocial behaviors: evidence from behavioral-genetic research. In J. C. Hall, J. C. Dunlap, T. Friedmann, \& V. van Heyningen (Eds.), Advances in genetics (Vol. 55, pp. 41-104). San Diego: Elsevier Academic.
Moffitt, T. E., \& Caspi, A. (2001). Childhood predictors differentiate life-course persistent and adolescence-limited antisocial pathways among males and females. Development and Psychopathology, 13(2), 355-375.

Moffitt, T. E., Caspi, A., Rutter, M., \& Silva, P. A. (2001). Sex differences in antisocial behaviour: conduct disorder, delinquency, and violence in the Dunedin Longitudinal Study. New York: Cambridge University Press.

Moffitt, T. E., Arseneault, L., Jaffee, S. R., Kim-Cohen, J., Koenen, K. C., Odgers, C. L., et al. (2008). Research review: DSM-V conduct disorder: research needs for an evidence base. Journal of Child Psychology and Psychiatry, 49(1), 3-33.

Munafò, M. R., Brown, S. M., \& Hariri, A. R. (2008). Serotonin transporter (5-HTTLPR) genotype and amygdala activation: a meta-analysis. Biological Psychiatry, 63(9), 852-857.

Muthén, L. K., \& Muthén, B. O. (2006). Mplus user's guide (4th ed.). Los Angeles: Muthén \& Muthén.

Newman, D. L., Moffitt, T. E., Caspi, A., \& Silva, P. A. (1998) Comorbid mental disorders: implications for treatment and sample selection. Journal of Abnormal Psychology, 107(2), 305-311.

Nylund, K., Bellmore, A., Nishina, A., \& Graham, S. (2007). Subtypes, severity, and structural stability of peer victimization: what does latent class analysis say? Child Development, 78(6), $1706-1722$.

Odgers, C. L., Caspi, A., Broadbent, J. M., Dickson, N., Hancox, R. J., Harrington, H., et al. (2007). Prediction of differential adult health burden by conduct problem subtypes in males. Archives of General Psychiatry, 64(4), 476-484.

Odgers, C. L., Moffitt, T. E., Broadbent, J. M., Dickson, N., Hancox, R. J., Harrington, H., et al. (2008). Female and male antisocial trajectories: from childhood origins to adult outcomes. Development and Psychopathology, 20(2), 673-716.

Olweus, D. (1979). Stability of aggressive reaction patterns in males: a review. Psychological Bulletin, 86(4), 852-875.

Patkar, A. A., Berrettini, W. H., Hoehe, M., Thornton, C. C., Gottheil, E., Hill, K., et al. (2002). Serotonin transporter polymorphisms and measures of impulsivity, aggression, and sensation seeking among African-American cocaine-dependent individuals. Psychiatry Research, 110(2), 103-115.

Petras, H., Schaeffer, C. M., Ialongo, N., Hubbard, S., Muthén, B., Lambert, S. F., et al. (2004). When the course of aggressive behavior in childhood does not predict antisocial outcomes in adolescence and young adulthood: an examination of potential explanatory variables. Development and Psychopathology, 16(4), 919-941.

Reboussin, B. A., Hubbard, S., \& Ialongo, N. S. (2007). Marijuana use patterns among African-American middle-school students: a longitudinal latent class regression analysis. Drug and Alcohol Dependence, 90(1), 12-24.

Reif, A., Rösler, M., Freitag, C. M., Schneider, M., Eujen, A., Kissling, C., et al. (2007). Nature and nurture predispose to violent behavior: serotonergic genes and adverse childhood environment. Neuropsychopharmacology, 32(11), 2375-2383.

Reinke, W. M., Herman, K. C., Petras, H., \& Ialongo, N. S. (2008). Empirically derived subtypes of child academic and behavior problems: co-occurrence and distal outcomes. Journal of Abnormal Child Psychology, 36(5), 759-770.

Rhee, S. H., \& Waldman, I. D. (2002). Genetic and environmental influences on antisocial behavior. A meta-analysis of twin and adoption studies. Psychological Bulletin, 128(3), 490-529.

Rindskopf, D. (2009). Latent class analysis. In R. E. Millsap \& A. Maydeu-Olivares (Eds.), The SAGE handbook of quantitative methods in psychology (pp. 199-218). Thousand Oaks: Sage.

Sakai, J. T., Lessem, J. M., Haberstick, B. C., Hopfer, C. J., Smolen, A., Ehringer, M. A., et al. (2006). Case-control and withinfamily tests for association between 5HTTLPR and conduct 
problems in a longitudinal adolescent sample. Psychiatric Genetics, 17(4), 207-214.

Schwartz, D., Proctor, L., \& Chien, D. (2001). The aggressive victim of bullying: emotional and behavioral dysregulation as a pathway to victimization by peers. In J. Juvonen \& S. Graham (Eds.), Peer harassment in school: the plight of the vulnerable and victimized (pp. 147-174). New York: Guilford.

Silverthorn, P., \& Frick, P. J. (1999). Developmental pathways to antisocial behavior: the delayed-onset pathway in girls. Development and Psychopathology, 11(1), 101-126.

Smith, C. A., Ireland, T. O., Thornberry, T. P., \& Elwyn, L. (2008). Childhood maltreatment and antisocial behavior: comparison of self-reported and substantiated maltreatment. American Journal of Orthopsychiatry, 78(2), 173-186.

Taylor, S. E., Way, B. M., Welch, W. T., Hilmert, C. J., Lehman, B. J., \& Eisenberger, N. I. (2006). Early family environment, current adversity, the serotonin transporter promoter polymorphism, and depressive symptomatology. Biological Psychiatry, 60(7), 671676.

Teicher, M. H., Andersen, S. L., Polcari, A., Anderson, C. M., Navalta, C. P., \& Kim, D. M. (2003). The neurobiological consequences of early stress and childhood maltreatment. Neuroscience and Biobehavioral Reviews, 27(1-2), 33-44.
Todd, R. D., Huang, H., Smalley, S. L., Nelson, S. F., Willcutt, E. G., Pennington, B. F., et al. (2005). Collaborative analysis of DRD4 and DAT genotypes in population-defined ADHD subtypes. Journal of Child Psychology and Psychiatry, 46(10), 1067-1073.

Uher, R., \& McGuffin, P. (2008). The moderation by the serotonin transporter gene of environmental adversity in the aetiology of mental illness: review and methodological analysis. Molecular Psychiatry, 13(2), 131-146.

Van Erp, A. M. M., \& Miczek, K. A. (2000). Aggressive behavior, increased accumbal dopamine and decreased cortical serotonin in rats. Journal of Neuroscience, 15, 9320-9325.

Van Goozen, S. H., Matthys, W., Cohen-Kettenis, P. T., Westenberg, H., \& van Engeland, H. (1999). Plasma monoamine metabolites and aggression: two studies of normal and oppositional defiant disorder children. European Neuropsychopharmacology, 9(1-2), 141-147.

Walrath, C. M., Petras, H., Mandell, D. S., Stephens, R. L., Holden, E. W., \& Leaf, P. J. (2004). Gender differences in patterns of risk factors among children receiving mental health services: latent class analyses. The Journal of Behavioral Health Services \& Research, 31(3), 297-311.

Willoughby, M., Kupersmidt, J., \& Bryant, D. (2001). Overt and covert dimensions of antisocial behavior in early childhood. Journal of Abnormal Child Psychology, 29(3), 177-187. 